\title{
An Objective Analysis Technique for Constructing Three-Dimensional Urban-Scale Wind Fields
}

\author{
William R. Goodin, ${ }^{1}$ Gregory J. McRae and John H. Seinfeld \\ Environmental Quality Laboratory, California Institute of Technology, Pasadena 91125
}

(Manuscript received 10 January 1979, in final form 8 September 1979)

\begin{abstract}
An objective analysis procedure for generating mass-consistent, urban-scale three-dimensional wind fields is presented together with a comparison against existing techniques. The algorithm employs terrain following coordinates and variable vertical grid spacing. Initial estimates of the velocity field are developed by interpolating surface and upper level wind measurements. A local terrain adjustment technique, involving solution of the Poisson equation, is used to establish the horizontal components of the surface field. Vertical velocities are developed from successive solutions of the continuity equation followed by an iterative procedure which reduces anomalous divergence in the complete field. Major advantages of the procedure are that it is computationally efficient and allows boundary values to adjust in response to changes in the interior flow. The method has been successfully tested using field measurements and problems with known analytic solutions.
\end{abstract}

\section{Introduction}

A key input to most urban-scale air pollution models is an accurately specified, mass-consistent wind field. In most practical situations numerical solution of the full Navier-Stokes equations is not feasible as a means of constructing such a field. As a result, simpler objective analysis procedures must be used. The most common approach for generating a gridded wind field consists of a two-step procedure, the first step of which is interpolation of the sparse and discrete measurements within the airshed to a finer mesh (Goodin et al., 1979). Once the initial field has been established, the next step is to employ an objective analysis procedure to adjust the wind vectors at each grid point so that appropriate physical constraints are satisfied. We present here a new technique for constructing three-dimensional velocity fields with a minimum of anomalous divergence.

\section{Previous work on wind field divergence reduction}

Only a limited number of divergence reduction procedures have appeared in the literature. Endlich (1967) used a point-iterative method to reduce the two-dimensional divergence in a wind field while retaining the vorticity in the original field. Fankhauser (1974) approached the three-dimensional divergence reduction problem from the point of view of accounting for measured data errors; in particular,

\footnotetext{
1 Present affiliation: Advanced Technology Group, Dames \& Moore, Los Angeles, CA 90024.
}

those which increase with altitude. Liu and Goodin (1976) adapted the technique of Endlich to a twodimensional mesoscale wind field. The flow field within the mixed layer was assumed to be vertically integrated and divergence was adjusted point by point with the capability of holding wind station values fixed. More recently, Sherman (1978) devised a procedure called MATHEW for constructing threedimensional mass-consistent wind fields. Based on the variational calculus approach of Sasaki (1958, 1970), the method involves solution of a Lagrange multiplier equation. A two-dimensional vertically integrated version of MATHEW called MASCON (Dickerson, 1978) was incorporated into the LIRAQ model (MacCracken, et al., 1978). The influences on the flow field of topography, surface roughness and temperature gradients were accounted for in a technique developed by Yocke et al. (1978) which uses empirically determined coefficients to weight the contributions of the various processes responsible for the flow field divergence.

While each of the above techniques has advantages, several shortcomings are apparent. In a number of cases the final form of the flow field is critically dependent on empirically chosen constants. Little guidance is given in the literature as to how some of these values can be developed for new regions. Another problem with some formulations is the initial estimates of horizontal velocities at region boundaries often force the nature of the interior flow solution. This can be a serious problem because, typically, few measurements are available 
at boundaries and so there can be large uncertainties associated with specification of the initial velocity field. From an operational point of view, none of the above techniques employ variable vertical grid spacing or terrain-following coordinate systems. The present paper introduces an algorithm which avoids most of the above limitations.

\section{The basic algorithm}

The present wind field generation algorithm consists of several basic steps. As a starting point, the region boundaries, vertical extent and basic grid cell sizes must be chosen. These are frequently dictated by the nature of the intended application. Once the grid has been established, the surface level velocity measurements and upper level wind and temperature data are interpolated to specify initial values for each computational point. The final step is to adjust the velocity field with the objective of minimizing anomalous divergence.

\section{a. Surface wind field generation}

The surface wind field is constructed from the measured data (converted to $u$ and $v$ components) by interpolation to a regular grid using inverse distance-squared weighting (Goodin et al., 1979). A fixed radius of influence $R$ is specified which indicates the distance beyond which the influence of a station's value is no longer felt. The influence of gross terrain features (e.g., mountain ranges) is accounted for by the use of barriers to flow during interpolation of the wind components. This procedure, however, does not incorporate the effects of local terrain features that have scales less than one grid cell length. Following the interpolation procedure, a local terrain-adjustment technique, which is similar to that of Anderson $(1971,1973)$, is used in the wind field calculation. This adjustment procedure involves solution of Poisson's equation

$$
\nabla^{2} \phi=\psi(x, y),
$$

where $\phi$ is a velocity potential and $\psi$ a forcing function based on layer thickness and terrain gradients. An evaluation of solution techniques for Eq. (1) was made which included a Fourier series method (Dorr, 1970), the successive overrelaxation (SOR) method (Roache, 1972), and the alternating-direction-implicit (ADI) method (Peaceman and Rachford, 1955). Based on efficiency, programming and accuracy considerations, the ADI method was chosen.

As a test of the surface wind field calculation procedure, $u$ and $v$ component data from 63 wind stations in the South Coast Air Basin (SCAB) in California for 1600 PST 26 June 1974 were interpolated to a $100 \times 50$ square grid. The grid spacing was $3.2 \mathrm{~km}$ and the radius of influence used was 25 grid squares (a size large enough to include at least two data points). The measured data together with barriers to flow are shown in Fig. 1. Terrain data were obtained at $200 \mathrm{ft}$ horizontal intervals from the National Cartographic Information Center, U.S. Geological Survey. From these data an average height for each $3.2 \mathrm{~km}$ square was then computed. Fig. 2 shows a three-dimensional plot of the terrain, the highest point of which is $\sim 3000 \mathrm{~m}$ MSL.

The results of the interpolation and terrain adjustment procedure are displayed in Fig. 3. For most stations, the agreement between computed and measured values, both for magnitude and direction, is quite good. The mean error in magnitude is $0.7 \mathrm{~m}$ $\mathrm{s}^{-1}$ which is less than a $20 \%$ relative error, while the mean direction error is $11.5^{\circ}$; this is within the $22.5^{\circ}$ sector to which the wind data are given. Among the stations operated by the South Coast Air Quality Management District (SCAQMD) (from which the most reliable data are obtained), the maximum error in magnitude occurs at Prado Park, a station which may be unduly influenced by localized channeling effects of Santa Ana Canyon. The computed magnitude is $5.1 \mathrm{~m} \mathrm{~s}^{-1}$, and the measured value is $6.7 \mathrm{~m}$ $\mathrm{s}^{-1}$. The largest error in magnitude occurring at any station is at CT33, a station operated by California Department of Transportation (CALTRANS). This station is in the vicinity of a convergence zone behind the Laguna Hills. The computed magnitude is $3.0 \mathrm{~m} \mathrm{~s}^{-1}$ and the measured magnitude is $5.8 \mathrm{~m} \mathrm{~s}^{-1}$.

The maximum error in direction among the SCAQMD stations occurs at Reseda, where the computed and measured vector differ by $44^{\circ}$. At 1600 PST, Reseda appeared to be near the location of the so-called San Fernando convergence zone, where air from Ventura encounters air from the Los Angeles basin. The measured vector at Reseda probably represents an average of a local fluctuating velocity and is, therefore, less representative of a $3.2 \mathrm{~km}$ square for that hour. The largest error in direction occurring at any station is at Station CT35 where the difference in direction is $69^{\circ}$. The location of this station, which is downwind of the pass near Camarillo and adjacent to the Santa Monica Mountains, may not be representative of a larger area.

All the station measurements and calculated results for the sample problem are displayed in Figs. $4 a$ and $4 b$. Two conclusions are apparent from an inspection of the scatter plots. The first is that there is little or no systematic bias in either the magnitude or direction of the calculated results. The second is that there is a high degree of correlation between observed and predicted, $r=0.86$ for the wind magnitudes and $r=0.90$ for direction.

\section{b. Interpolation of the upper level wind and temperature data}

Before the transport of urban pollutants can be adequately modeled some knowledge of the vertical 


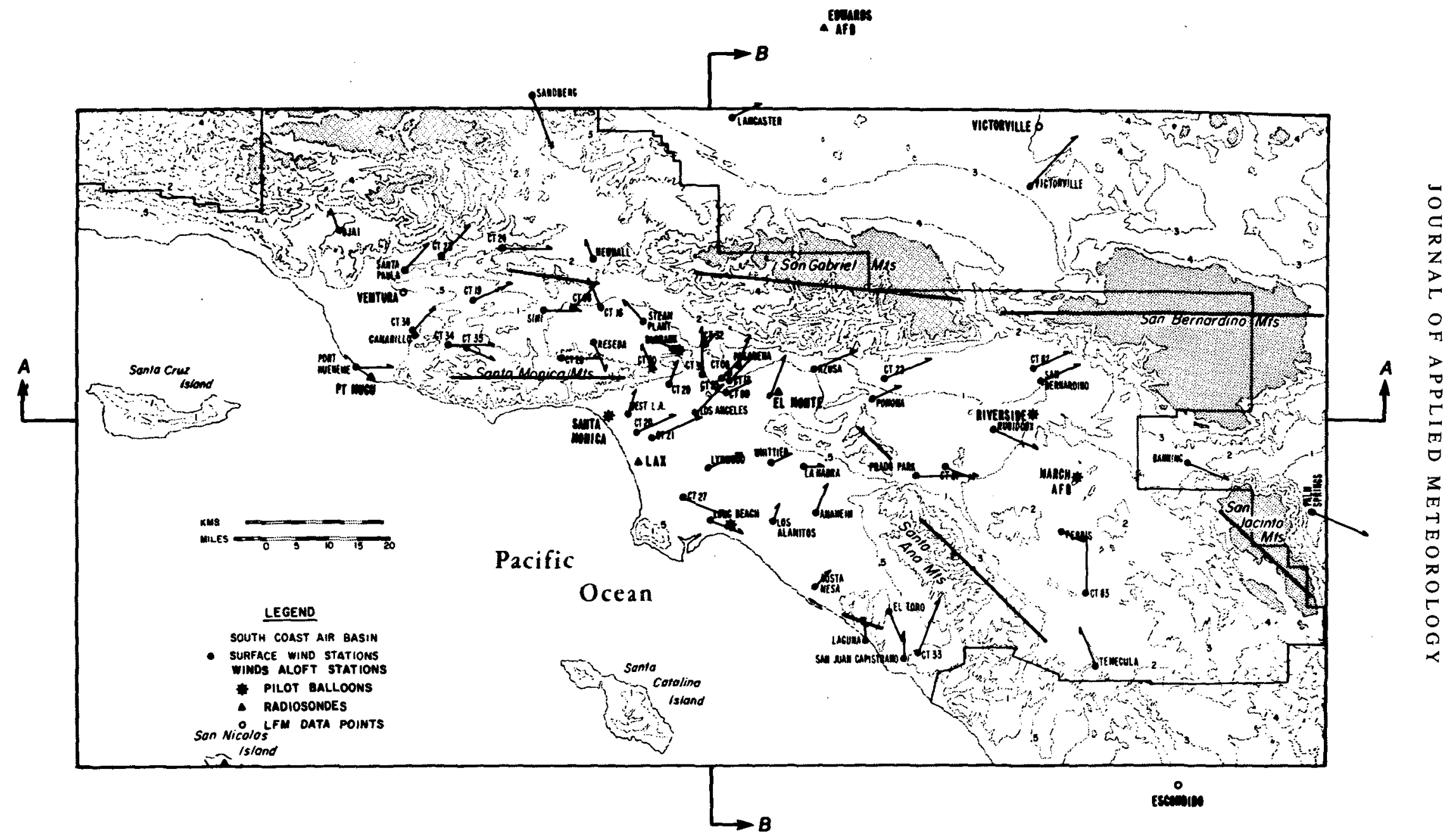

FIG. 1. Measured hourly-averaged wind data for 1600 PST 26 June 1974. Barriers to flow are indicated by solid lines. The largest measured velocity is $7 \mathrm{~m} \mathrm{~s}^{-1}$. 


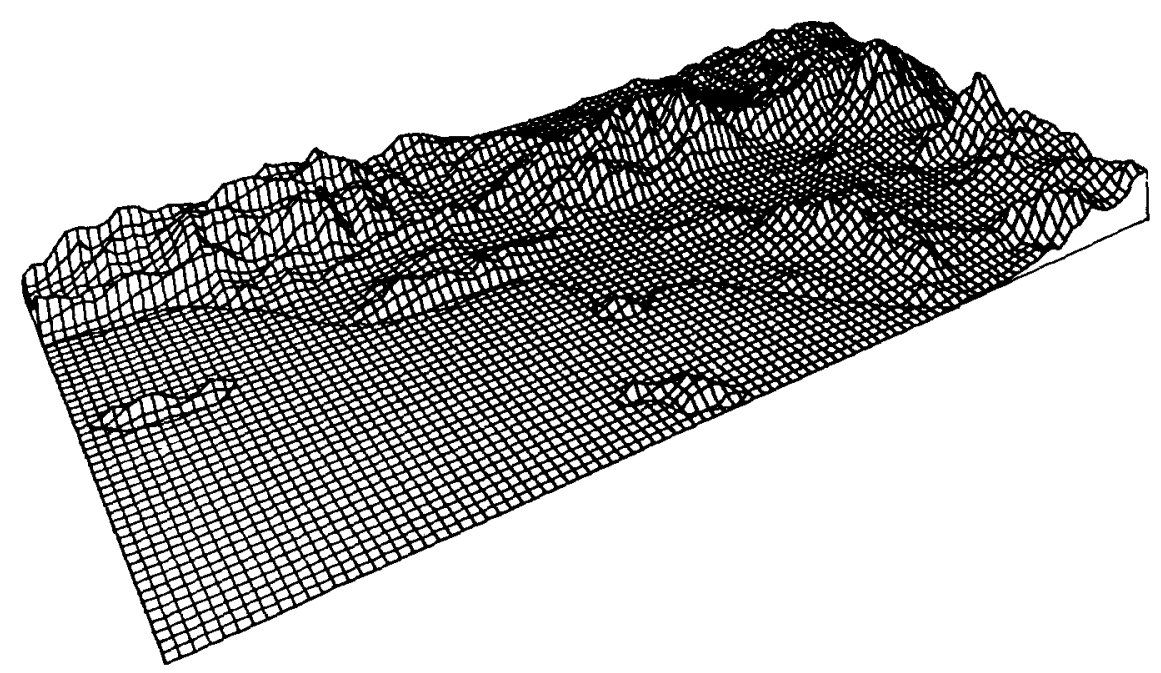

Frg. 2. Topography of Los Angeles basin viewed from the southwest.

temperature structure and the three-dimensional flow field is required. These quantities are known with much less precision than the surface quantities since fewer measurements are customarily available. As an example of available data in the Los Angeles area, Fig. 1 shows the measurement stations for upper level data in the SCAB. This data set includes stations in operation: Los Angeles International Airport (LAX), Pt. Mugu, San Nicolas Island, El Monte, Riverside and Edwards Air Force Base (off grid); sites with data calculated for the days of interest using the Limited-Area Fine Mesh Model (Gerrity, 1976): Victorville, Escondido, Ventura; and stations which have recorded upper level data in the past, providing "typical" data: Long Beach, Burbank, Santa Monica and March Air Force Base. An average of two measurements per day are available at each station except for El Monte where an acoustic sounder records the depth of the mixed layer continuously.

The approach taken for spatial interpolation of mixing depth and upper level wind data is slightly different from that used for the surface quantities. Imprecision in the measured data makes a highly accurate interpolation procedure unnecessary; as a result $r^{-1}$ weighting was chosen since it produces a smoother field than $r^{-2}$ weighting. In performing the interpolation of mixing depth, the height above sea level is first computed at all grid points. The height of the terrain surface is then subtracted to give mixing depth above the surface. This procedure is used because the height of the mixed layer above sea level tends to be a smooth surface while the terrain changes more abruptly. Contours of mixing depth tend to follow the coastline since the degree of heating of air moving inland depends mainly on the distance travelled over land. The mixing depth data for 1600 PST 26 June 1974 were interpolated using the $r^{-1}$ procedure and then smoothed using a simple five-point filter in which the new value at a given point is the average of the value at the point itself and the values at the four adjacent points,

$$
\begin{aligned}
& h_{i j}^{n+1}=0.20\left(h_{i j}^{n}+h_{i-1 j}^{n}+h_{i+1 j}^{n}\right. \\
& \left.+h_{i j+1}^{n}+h_{i j-1}^{n}\right) .
\end{aligned}
$$

The maximum depth was set at $1100 \mathrm{~m}$ since a depth greater than this is generally assumed to be unlimited. A three-dimensional plot of mixing depth above sea level is shown in Fig. 5. The mixing depth follows the contours of the terrain at high elevations since negative mixing heights cannot occur.

In order to follow pollutants as they move above the mixed layer, the top of the region was set at a high level (above the mixed layer). The top of the mixed layer was allowed to fluctuate both temporally and spatially within this region. Its only real purpose is a reference height above which vertical diffusion is very small. In addition, to eliminate the difficulty in specifying vertical velocity boundary conditions, a coordinate system which follows the terrain surface was chosen rather than sea level based coordinates. The transformation from sea level to terrain-following coordinates produces a new vertical velocity, $W$, i.e.,

$$
\begin{aligned}
W=w-u\left(\frac{\partial h}{\partial x}\right. & \left.+\rho \frac{\partial \Delta H}{\partial x}\right) \\
& -v\left(\frac{\partial h}{\partial y}+\rho \frac{\partial \Delta H}{\partial y}\right)-\rho \frac{\partial \Delta H}{\partial t},
\end{aligned}
$$

where $\Delta H(x, y, t)=H(x, y, t)-h(x, y)$ is the height of the top of the region above the terrain surface, and $\rho$ is the new vertical coordinate $(0 \leqslant \rho \leqslant 1)$. 


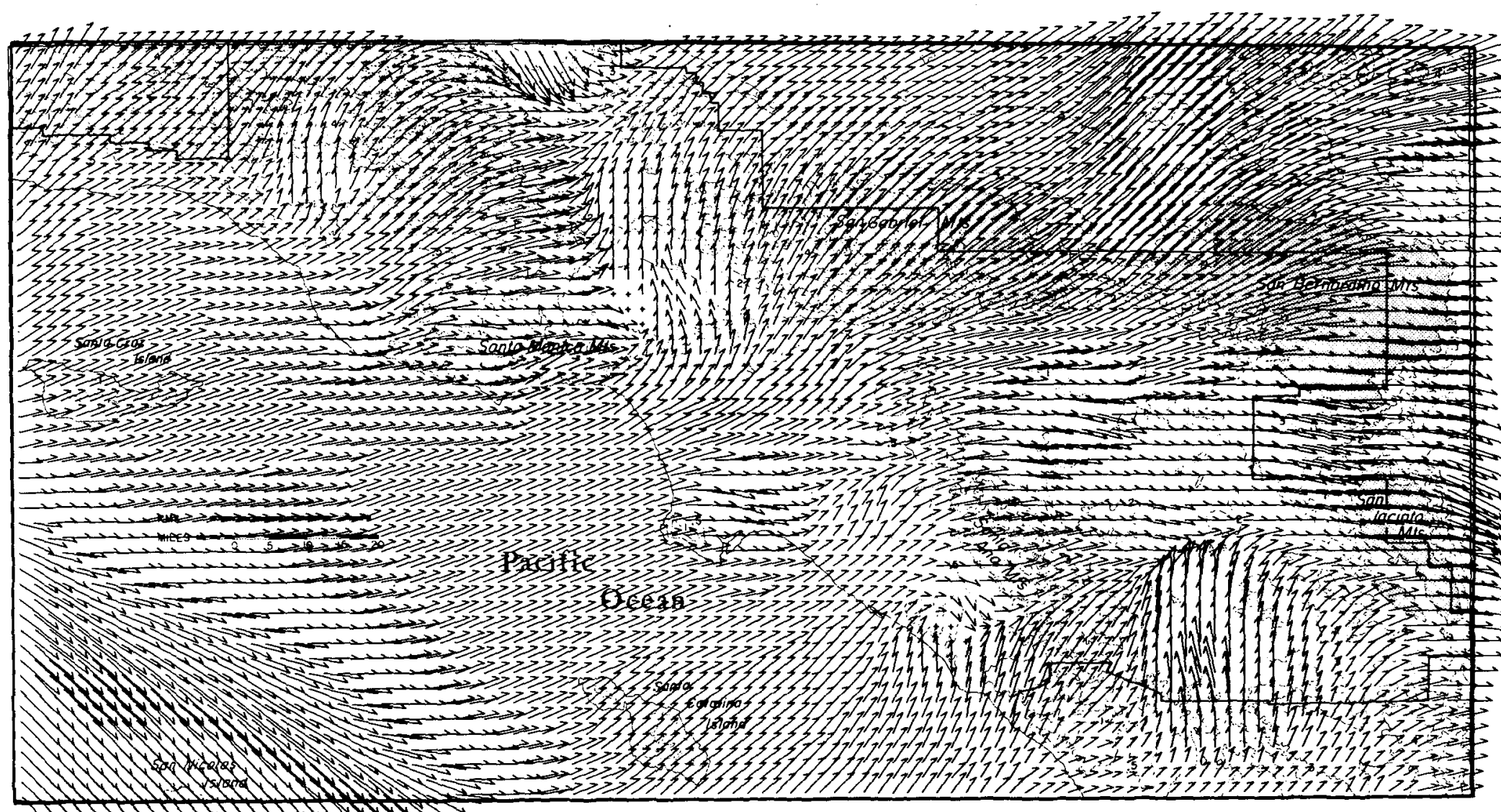

Whlm

FIG. 3. Flow field in the surface layer following interpolation and adjustment for terrain effects. 
Fig. 6a shows the general case where $\Delta H$ is a function of space as well as time. In order to eliminate complications introduced into the advection scheme by nonparallelopiped grid volumes in $x, y, z$ space, $\Delta H$ is used for normalization. Figs. $6 \mathrm{~b}$ and $6 \mathrm{c}$ show the transformation from the $x, y, z$ space to $x, y$, $\rho$ space.

In the new coordinate system, the continuity equation is

$$
\frac{\partial W}{\partial \rho}+\frac{\partial(u \Delta H)}{\partial x}+\frac{\partial(v \Delta H)}{\partial y}=0
$$

Given the horizontal velocities at each vertical level from $r^{-1}$ interpolation of the measured data, $W$ can be calculated at each level using Eq. (4). Unfortunately, this simple solution produces unrealistically large values of $W$ at the top of the region since all residual divergence in the field is propagated upward. Therefore, a procedure is required that will reduce the divergence in the flow field to an acceptable level while maintaining small upper level vertical velocities.

\section{c. New divergence reduction procedure}

Once the surface level flow field has been established and the upper level wind data have been interpolated to the three-dimensional grid, the next step is to reduce the divergence in the total flow field. The proposed procedure involves three steps:

1) The divergence in each of the interpolated $u$ and $v$ fields at each vertical level above the lowest layer is first reduced using a slightly modified version of the simple five-point filter discussed above. The equation for smoothing is

$$
\begin{aligned}
& u_{i j}^{n+1}=0.20\left(u_{i j}^{n}+u_{i+1 j}^{n}+u_{i-1 j}^{n}\right. \\
& \left.+u_{i j+1}^{n}+u_{i j-1}^{n}\right)\left(1-\alpha_{k}\right)+\alpha_{k} u_{i j}^{n},
\end{aligned}
$$

where $\alpha_{k}$ is a parameter which allows the user to keep the measured velocity at station $k$ fixed $\left(\alpha_{k}=1\right)$ or keep only some of its original influence $\left(\alpha_{k}<1\right)$. This parameter is zero at all non-measuring station points. This first step is designed to reduce as much of the anomalous divergence as possible. The number of passes through the smoothing step is related to the relative atmospheric stability at that level and will be determined empirically. A relatively unstable (generally near ground level) layer requires few iterations since less of the divergence present is anomalous, while a more stable upper layer must be smoothed more times. The more smoothing a field of values is subjected to, the more initial anomalous divergence is disșipated horizontally within that layer, i.e., the more the vertical velocity above that layer (which will be computed from the divergence within the layer) will be suppressed.
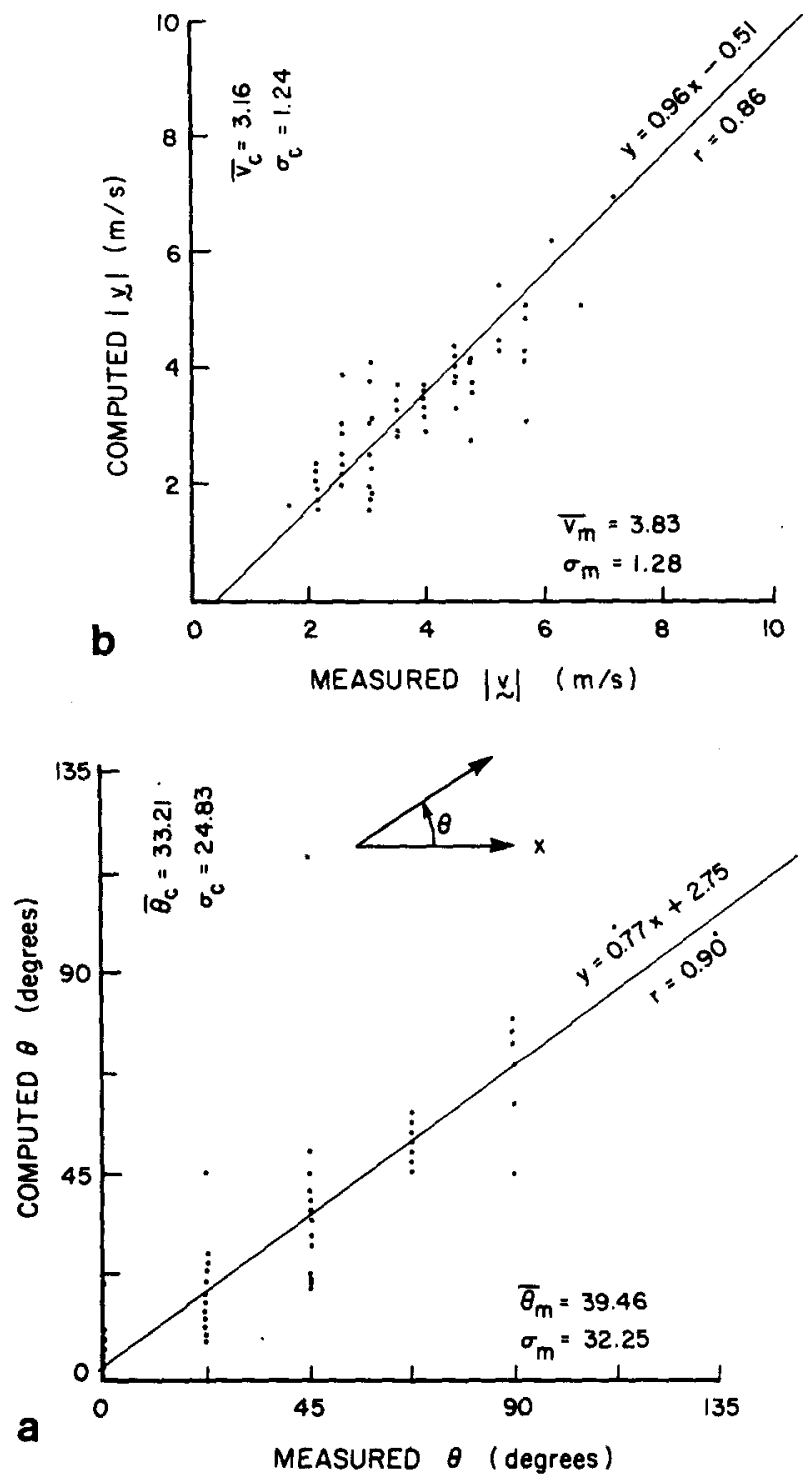

FIG. 4. Comparison of field observations against calculated results: (a) Wind direction, (b) wind magnitude.

2) Following this initial smoothing step, the vertical velocity above each layer is computed from the divergence within that layer. The layers are temporarily disconnected from each other during this calculation so that the calculated vertical velocity above a layer depends only upon the divergence within that layer. This prevents velocities at the top of the region from becoming unrealistically large. These vertical velocities will be held fixed throughout the rest of the divergence reduction procedure.

3) The final refinement reduces the remaining divergence which exists within each layer by application of a two-dimensional technique to each layer similar to that of Liu and Goodin (1976). The equation solved is (with $\Delta H=$ constant) 


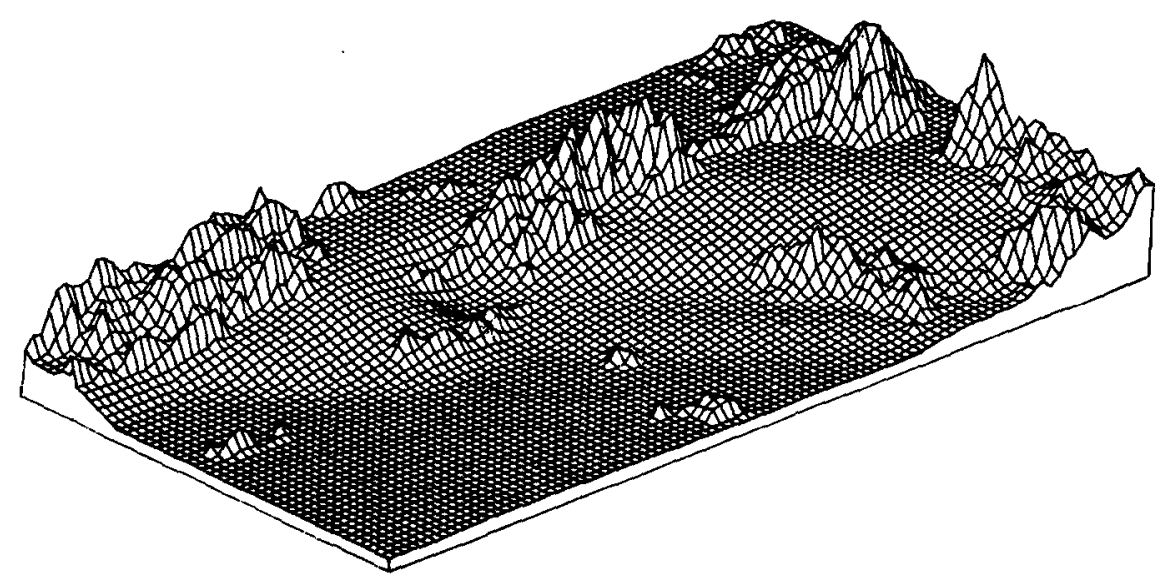

FIG. 5. Mixing heights above sea level computed from measured data for 1600 PST 26 June 1974.

$$
\frac{\partial W}{\partial \rho}+\Delta H\left(\frac{\partial u}{\partial x}+\frac{\partial v}{\partial y}\right)=D_{R}(x, y, \rho),
$$

where $D_{R}(x, y, \rho)$ is a measure of the remaining divergence. At grid point $(i, j, k)$, Eq. (6) can be written as

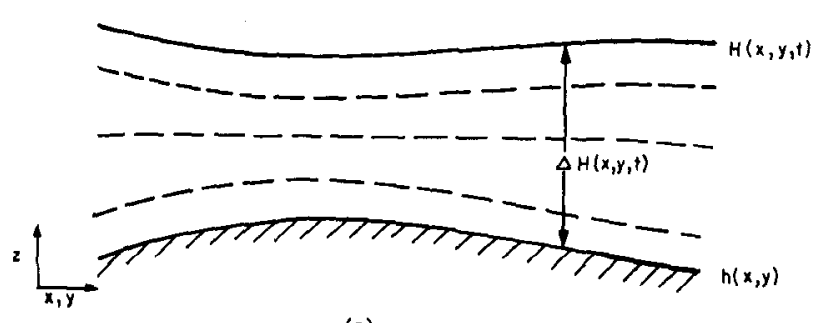

(a)
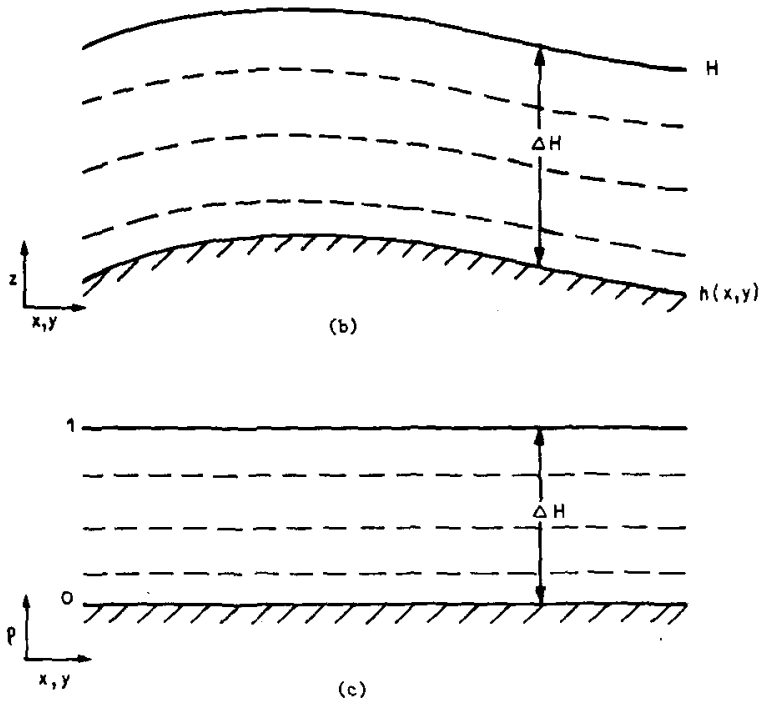

FIG. 6. A terrain-following coordinate system: (a) general case $H=H(x, y, t)$; (b) $H$ is a constant height above the terrain; (c) transformed $x, y, \rho$ coordinate system.

$$
\begin{aligned}
& D_{i j k}^{n+1}=\frac{W_{i, j, k+1 / 2}-W_{i, j, k-1 / 2}}{\Delta \rho} \\
&+\Delta H\left[\frac{u_{i+1 / 2, j, k}^{n+1}-u_{i-1 / 2, j, k}^{n+1}}{\Delta x}\right. \\
&\left.+\frac{v_{i, j+1 / 2, k}^{n+1}-v_{i, j-1 / 2, k}^{n+1}}{\Delta y}\right],
\end{aligned}
$$

where the superscript $n+1$ indicates the values are computed for the $(n+1)$ st iteration, and the subscript $R$ is dropped from $D_{R}$ for convenience.

To remove the divergence at the point $(i, j, k)$, adjustments are made to the $u$ values at $(i+1 / 2, j, k)$ and $(i-1 / 2, j, k)$ and the $v$ values at $(i, j+1 / 2, k)$ and $(i, j-1 / 2, k)$ in order that the divergence is exactly zero at $(i, j, k)$. Since this procedure will add additional divergence to surrounding points, the whole grid must be scanned iteratively. The adjustments to the velocity components are

$$
\left.\begin{array}{rl}
u_{i+1 / 2, j, k}^{n+1} & =u_{i+1 / 2, j, k}^{n}+u_{T} \\
u_{i-1 / 2, j, k}^{n+1} & =u_{i-1 / 2, j, k}^{n}-u_{T} \\
v_{i, j+1 / 2, k}^{n+1} & =v_{i, j+1 / 2, k}^{n}+v_{T} \\
v_{i, j-1 / 2, k}^{n+1} & =v_{i, j-1 / 2, k}^{n}-v_{T}
\end{array}\right\},
$$

where $u_{T}$ and $v_{T}$ are the adjustment velocities. These velocities are computed by substitution in Eq. (7),

$$
0=D_{i j k}^{n}+\Delta H\left(\frac{2 u_{T}}{\Delta x}+\frac{2 v_{T}}{\Delta y}\right) .
$$

Assuming that $\Delta y=\Delta x$ and that the velocity adjustments are equally weighted in each direction, Eq. (9) can be solved to give

$$
u_{T}=\frac{-D_{i j k}^{n} \Delta x}{4 \Delta H} \text {. }
$$




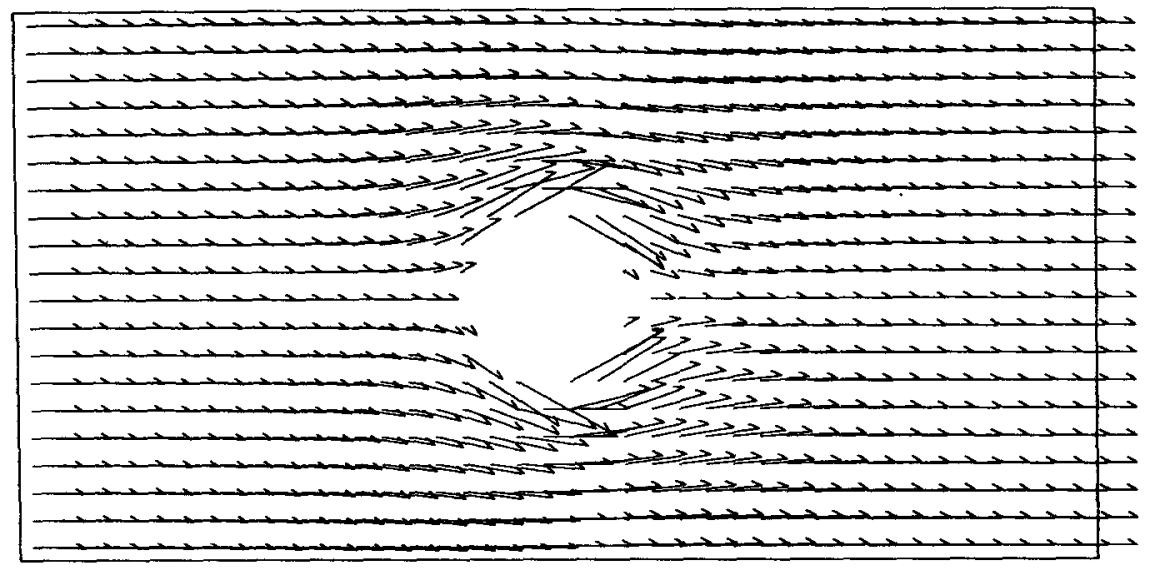

Fig. 7. Idealized three-dimensional flow field-initial state in layer 1.

Thus, the complete three-dimensional divergence reduction procedure consists of 1) smoothing at each level using an empirically determined number of smoothing passes based on local atmospheric stability, 2) followed by solution of Eq. (7) at each level for $W_{i, j, k+1 / 2}$, temporarily assuming $W_{i, j, k-1 / 2}$ is zero; and 3) Eqs. (7), (10) and (6) are then solved repeatedly using the calculated values for $W$ until the maximum divergence is reduced to an acceptable level, i.e., the magnitude of the divergence should be less than the local vertical velocity and less than the estimated errors in the horizontal velocity components.

The interaction between the flow field and the change in depth of the mixed layer has not been accounted for in the above procedure because of a lack of upper air data, i.e., mixing depth and vertical velocity are never measured simultaneously, and because attempts to tie the vertical cell heights to the mixing depth resulted in large horizontal wind velocities as the mixing depth approached zero.

\section{Test of present divergence reduction procedure}

A hypothetical flow field was constructed to test the divergence reduction procedure just discussed and estimate the approximate number of smoothing passes corresponding to each Pasquill stability class. The grid chosen was $40 \times 20 \times 2$ points. The upper layer contained uniform horizontal flow at $5 \mathrm{~m} \mathrm{~s}^{-1}$. In the lower layer the flow consisted of potential flow around a circular disk located at the center of the grid. Each layer was of equal thickness with a horizontal grid spacing of $2 \mathrm{~km}$. Fig. 7 shows the initial flow pattern in the lower layer.

The test consisted of reducing the divergence in the flow following removal of the disk. First, the smoothing step reduced the gross divergence in the lower layer (the upper layer required no smoothing). The vertical velocity between the layers was then calculated from the divergence in the lower layer using Eq. (10), temporarily assuming zero velocity at the bottom of that layer. (The vertical velocity above layer 2 was identically zero since there was no divergence present initially.) Finally, the refined, iterative divergence-reduction step was performed within each layer as described in Section 3c.

The results for number of smoothing passes ranging from 1 to 40 are shown in Table 1 . As expected, the final divergence, as well as maximum $W$, is a strong function of number of initial smoothing passes. The iterative divergence reduction procedure then reduces the remaining divergence by a factor of 20-40 after 100 iterations. A maximum vertical velocity of $0.28 \mathrm{~m} \mathrm{~s}^{-1}$ approximately corresponds to vertical velocities observed within the mixed layer during the daytime hours in the Los Angeles Basin (Angell et al., 1972), while typical subsidence motion within the inversion is on the order of $0.02 \mathrm{~m} \mathrm{~s}^{-1}$.

The set of upper air data collected in Los Angeles on 1600 PST 26 June 1974 was then used to test the present procedure. The data measurement locations are indicated in Fig. 1. Five vertical levels were

TABLE 1. Results of the present divergence reduction procedure on an idealized data set.

\begin{tabular}{cccc}
\hline & \multicolumn{4}{c}{$\begin{array}{c}\text { Maximum divergence } \\
\text { in layer 2 }\end{array}$} & \\
\cline { 2 - 4 } $\begin{array}{c}\text { Number of } \\
\text { smoothing } \\
\text { passes }\end{array}$ & $\begin{array}{c}\text { Following } \\
\text { initial } \\
\text { smoothing } \\
\left(\times 10^{6} \mathrm{~s}^{-1}\right)\end{array}$ & $\begin{array}{c}\text { Following } \\
100\end{array}$ & $\begin{array}{c}\text { Maximum } W \\
\left(\times 10^{6} \mathrm{~s}^{-1}\right)\end{array}$ \\
\hline 1 & 350.0 & 8.3 & $\begin{array}{c}\text { above layer 1 } \\
\left(\mathrm{m} \mathrm{s}^{-1}\right)\end{array}$ \\
\hline 5 & 41.7 & 1.1 & 0.28 \\
10 & 16.7 & 0.3 & 0.04 \\
20 & 11.1 & 0.3 & 0.01 \\
40 & 5.5 & 0.3 & 0.004 \\
\hline
\end{tabular}


TABLE 2. Results of present divergence reduction procedure on wind data from 1600 PST 26 June 1974.

\begin{tabular}{|c|c|c|c|c|c|}
\hline \multirow[b]{2}{*}{ Layer } & \multirow[b]{2}{*}{$\begin{array}{l}\text { Thickness } \\
\text { of layer } \\
\text { (m) }\end{array}$} & \multirow[b]{2}{*}{$\begin{array}{l}\text { Number of smoothing } \\
\text { passes during } \\
\text { first step }\end{array}$} & \multicolumn{3}{|c|}{ rms divergence } \\
\hline & & & $\begin{array}{l}\text { After initial } \\
\text { smoothing } \\
\left(\times 10^{6} \mathrm{~s}^{-1}\right)\end{array}$ & $\begin{array}{l}\text { After } 100 \\
\text { iterations } \\
\left(\times 10^{6} \mathrm{~s}^{-1}\right)\end{array}$ & $\begin{array}{l}\text { After } 200 \\
\text { iterations } \\
\left(\times 10^{6} \mathrm{~s}^{-1}\right)\end{array}$ \\
\hline 1 & 50 & 0 & 151 & 149 & 148 \\
\hline 2 & 150 & 5 & 27 & 20 & 20 \\
\hline 3 & 300 & 10 & 27 & 17 & 14 \\
\hline 4 & 550 & 20 & 25 & 14 & 11 \\
\hline 5 & 450 & 20 & 51 & 28 & 20 \\
\hline
\end{tabular}
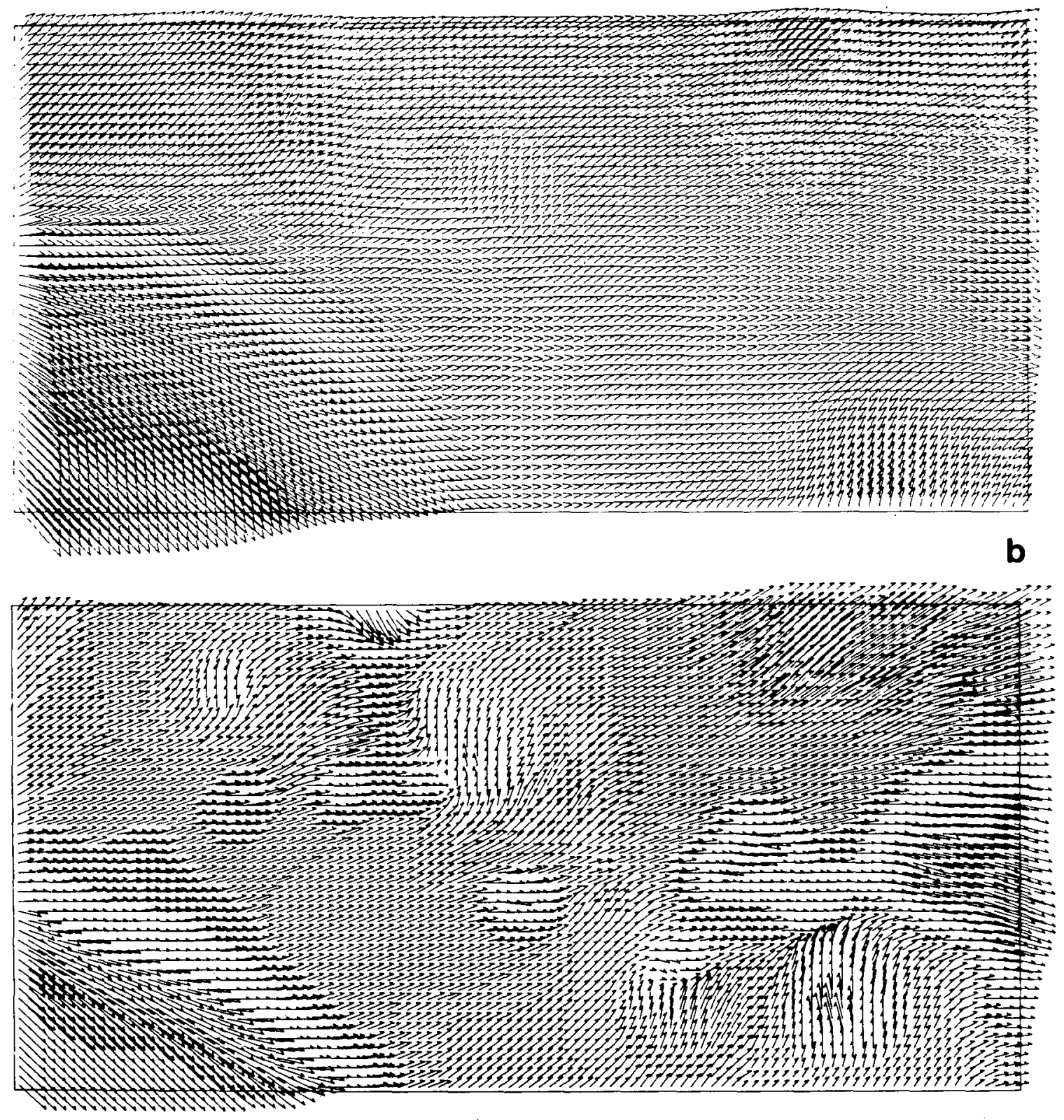

Fig. 8. (a) Horizontal flow field in layer 2 ( $550 \mathrm{ft}$ above terrain) at 1600 PST 26 June 1974 and (b) horizontal flow field in layer 3 (1200 ft above terrain) at 1600 PST 26 June 1974. 

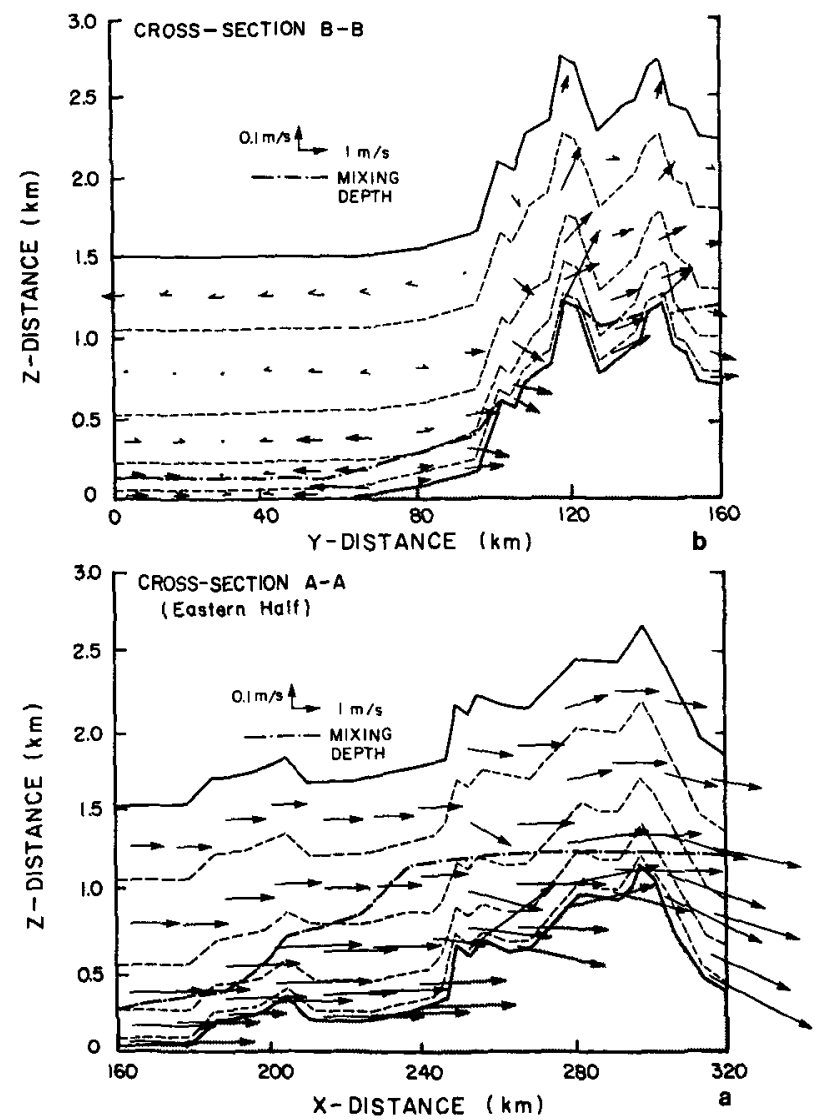

FIG. 9. Vertical velocity cross sections corresponding to locations indicated in Fig. 1. (Note exaggeration of vertical scale.) (a) Eastern half of cross section AA, (b) cross section BB. chosen with thicknesses of $50,150,300,550$ and $450 \mathrm{~m}$, respectively. The lowest layer, of depth $50 \mathrm{~m}$, was the surface layer, the flow pattern of which had been calculated previously from the surface data network. The interpolated $u$ and $v$ fields in layers $2-5$ were smoothed $5,10,20$ and 20 times, respectively. These numbers were obtained empirically from the calculation of the flow around the disk and correspond approximately to Pasquill stability classes B, $D$ and $E$.

The results of the calculation procedure are displayed in Table 2 and Figs. $8 \mathrm{a}, 8 \mathrm{~b}, 9 \mathrm{a}$ and $9 \mathrm{~b}$. The algorithm reduced the divergence to $<0.001 \mathrm{~s}^{-1}$ in all layers; in the vicinity of downtown Los Angeles, an area of relatively flat terrain, the divergence is of order $10^{-5} \mathrm{~s}^{-1}$. The largest divergence in each layer occurs over mountainous regions, especially the San Jacinto and San Gabriel mountains. In these areas, upper air data are nonexistent, so the interpolation procedure has generated a smoothed flow field which does not accurately reflect the influence of the steep terrain in these regions. Most of the divergence was reduced during the initial smoothing step. The last two columns in Table 2 indicate that 100 iterations were sufficient to refine the divergence reduction during the second step. Very little additional reduction was obtained after 200 iterations. The algorithm has been extensively tested against analytic problems, the results of field releases of $\mathrm{SF}_{6}$ and has been used to generate 72 different hours of wind fields for use in the modeling study by McRae et al. (1980).

TABLE 3. Comparison of attributes of three-dimensional divergence reduction procedures.

\begin{tabular}{|c|c|c|}
\hline Attribute & Present technique & MATHEW \\
\hline Coordinate system & Terrain-following coordinates & Coordinate system parallel to sea level \\
\hline $\begin{array}{l}\text { Treatment of flow over complex } \\
\text { terrain }\end{array}$ & $\begin{array}{l}\text { Barriers to flow are used during interpolation } \\
\text { procedure. Surface layer flow is adjusted using } \\
\nabla^{2} \phi=D \text {, where } D \text { is magnitude of vertical } \\
\text { perturbation. }\end{array}$ & $\begin{array}{l}\text { Obstacle cells are used to represent } \\
\text { terrain. They are treated as no-flow- } \\
\text { through boundaries. }\end{array}$ \\
\hline Interpolation procedure & $\begin{array}{l}1 / r^{2} \text { weighting of station data at surface. } 1 / r \\
\text { weighting at each level above surface. }\end{array}$ & $\begin{array}{l}1 / r^{2} \text { weighting at surface. Upper level } \\
\text { values are obtained from synoptic } \\
\text { analysis. }\end{array}$ \\
\hline $\begin{array}{l}\text { Treatment of horizontal boundary } \\
\text { conditions during divergence } \\
\text { reduction procedure }\end{array}$ & $\begin{array}{l}\text { Normal component of velocity at boundary is } \\
\text { adjusted according to value at adjacent interior } \\
\text { point. (Same procedure as at all other interior } \\
\text { points.) }\end{array}$ & $\begin{array}{l}\text { Program accepts } \partial \lambda / \partial n=0 \text { or } \lambda=0 \text { as } \\
\text { boundary conditions. Derivative is } \\
\text { approximated by three-point } \\
\text { difference. }\end{array}$ \\
\hline Treatment of atmospheric stability & $\begin{array}{l}\text { Number of smoothing passes through interpolated } \\
\text { field at each vertical level is related to the } \\
\text { stability at that level. Amount of smoothing } \\
\text { required for a given stability class is obtained } \\
\text { empirically. }\end{array}$ & $\begin{array}{l}\text { Gaussian precision moduli, } \alpha_{1}, \alpha_{2}, \\
\text { which are functions of measurement } \\
\text { errors must be determined } \\
\text { empirically. }\end{array}$ \\
\hline Variable vertical grid spacing & Yes & No \\
\hline Computer time required & $\begin{array}{l}25000 \text { points }(100 \times 50 \times 5) \\
\text { Divergence } \rightarrow 10^{-4} \mathrm{~s}^{-1} \\
5 \text { min on IBM } 370\end{array}$ & $\begin{array}{l}23000 \text { points }(25 \times 33 \times 28) \\
\text { Divergence } \rightarrow 10^{-12} \mathrm{~s}^{-1} \\
2-5 \text { min on } \mathrm{CDC} 7600(20-50 \mathrm{~min} \text { on } \\
\text { IBM } 370)\end{array}$ \\
\hline
\end{tabular}




\section{Comparison with previous divergence reduction procedures}

Table 3 presents a comparison of the proposed method with MATHEW. Each procedure uses an inverse-distance weighting procedure to interpolate the measured values. MATHEW, however, relies on a synoptic analysis to determine the horizontal velocities at the upper boundary. If a vertical profile of wind speed and direction is not available, a linear variation is assumed between the surface layer winds and the upper boundary.

The use of obstacle cells in MATHEW for flow over complex terrain affects the computer time required for solution, since the computer time increases with the complexity of the terrain. The use of terrain-following coordinates in the present technique avoids this difficulty. A major advantage of the present technique is that it allows the boundary values to adjust in response to the interior flow. Each of the techniques requires an empirically determined parameter. Its value is calculated based on atmospheric stability. The choice of the value to be used in each procedure must be determined by the experience of the user.

\section{Conclusions}

A new technique for constructing a threedimensional, urban-scale, mass-consistent wind field has been introduced. The interpolation method relies on measured upper air data (when available) for constructing the flow field. If little or no upper air data are available, the user may construct velocity profiles using some assumed profile such as a power law for input to the program. The problem of large vertical velocity at the top of the region has been avoided by reducing divergence significantly at the lower levels rather than allowing it to propagate out of the top of the region. Variable vertical grid spacing is also permitted allowing the user greater flexibility in the concentration calculations. The present technique is easy to implement, computationally efficient, and offers promise as an attractive method for routine meteorological applications.

Acknowledgments. Portions of this work were supported by the California Air Resources Board under Contract A5-046-87, and by Institutional
Grant EY-76-G-03-1305 from the Department of Energy.

\section{REFERENCES}

Anderson, G. E., 1971: Mesoscale influences on wind fields. J. Appl. Meteor., 10, 377-386.

_- 1973: A mesoscale windfield analysis of the Los Angeles Basin. EPA-650/4-73-001, The Center for Environment and Man, Inc., Hartford, Conn., 56 pp.

Angell, J. K., D. H. Pack, L. Machta, C. R. Dickson and W. H. Hoecker, 1972. Three-dimensional air trajectories determined from tetroon flights in the planetary boundary layer in the Los Angeles Basin. J. Appl. Meteor., 11, 451-471.

Dickerson, M. H., 1978: MASCON-A mass consistent atmospheric flux model for regions with complex terrain. J. Appl. Meteor., 17, 241-253.

Dorr, F. W., 1970: The direct solution of the discrete Poisson equation on a rectangle. SIAM Rev., 12, 248-263.

Endlich, R. M., 1967: An iterative method for altering the kinematic properties of wind field. J. Appl. Meteor., 6, 837-844.

Fankhauser, J. C., 1974: The derivation of consistent fields of wind and geopotential height from mesoscale rawinsonde data. J. Appl. Meteor., 13, 637-646.

Gerrity, J. F., Jr., 1977: The LFM model: A documentation. NOAA Tech. Memo. NWS NMC 60, National Meteorological Center, 66 pp.

Goodin, W. R., G. J. McRae and J. H. Seinfeld, 1979: A comparison of interpolation methods for sparse data: Application to wind and concentration fields. J. Appl. Meteor., $18,761-771$.

Liu, C. Y., and W. R. Goodin, 1976: An iterative algorithm for objective wind field analysis. Mon. Wea. Rev., 104, 784-792.

MacCracken, M. C., D. J. Wuebbles, J. J. Walton, W. H. Duewer and K. E. Grant, 1978: The Livermore regional air quality model: I. Concept and development. J. Appl. Meteor., 17, 254-272.

McRae, G. J., W. R. Goodin and J. H. Seinfeld, 1980. Development of a second generation mathematical model of photochemical air pollution. Final Report to the California Air Resources Board under Contract A5-046-87.

Peaceman, D. W., and H. H. Rachford, Jr., 1955: The numerical solution of parabolic and elliptic differential equations. J. SIAM, 3, 28-41.

Roache, P. J., 1972: Computational Fluid Dynamics. Hermosa Publ., 434 pp.

Sasaki, Y., 1958: An objective analysis based on the variational method. J. Meteor. Soc. Japan, 36, 77-88.

—_, 1970: Some basic formalisms in numerical variational analysis. Mon. Wea. Rev., 98, 875-898.

Sherman, C. A., 1978: A mass-consistent model for wind fields over complex terrain. J. Appl. Meteor., 17, 312-319.

Yocke, M. A., M. K. Liu and J. L. McElroy, 1978: The development of a three-dimensional wind model for complex terrain. Proc. Joint Conf. Application of Air Pollution Meteorology, Salt Lake City, Amer. Meteor. Soc., 209-214. 